\title{
Surgical repair of acute type $A$ aortic dissection: Continuous pulmonary perfusion during retrograde cerebral perfusion prevents lung injury in a pilot study
}

\author{
Luca Salvatore De Santo, MD \\ Gianpaolo Romano, $\mathrm{MD}^{\mathrm{a}}$ \\ Cristiano Amarelli, MD \\ Francesco Onorati, MDa \\ Michele Torella, MD ${ }^{a}$ \\ Attilio Renzulli, MD, FECTS ${ }^{a}$ \\ Nicola Galdieri, $\mathrm{MD}^{\mathrm{b}}$ \\ Maurizio Cotrufo, MD, FECTS ${ }^{a}$
}

From the Department of Cardio-Thoracic and Respiratory Sciences ${ }^{\mathrm{a}}$ and the Cardiac Surgery Intensive Care Unit, ${ }^{\mathrm{b}}$ V. Monaldi Hospital, Second University of Naples, Naples, Italy.

Supported by a 1999 grant from MURST, the Italian Ministry for University and Scientific Research.

Presented at the Sixteenth Annual Meeting of The European Association for CardioThoracic Surgery, Monte Carlo, Sept 2225, 2002.

Received for publication Oct 11, 2002; revisions requested Nov 6, 2002; revisions received Dec 27, 2002; accepted for publication Jan 22, 2003.

Address for reprints: Luca Salvatore De Santo, MD, Viale Colli Aminei 491, 80129, Naples, Italy (E-mail: luca.desanto@ ospedalemonaldi.it).

J Thorac Cardiovasc Surg 2003;126:826-31

Copyright (C 2003 by The American Association for Thoracic Surgery

0022-5223/2003\$30.00+0

doi:10.1016/S0022-5223(03)00583-X
Objective: Postoperative respiratory failure is a frequent and serious complication in patients with type A acute aortic dissection operated on with deep systemic hypothermia. Interaction between neutrophils and pulmonary endothelium along with ischemic insult and reperfusion are the major determinants of lung injury. The aim of this prospective study was to evaluate the effect of continuous pulmonary perfusion during retrograde cerebral perfusion on lung function.

Methods: Twenty-two patients referred for acute type A aortic dissection, who were free from preoperative respiratory dysfunction, were assigned prospectively and alternately to one of 2 treatment groups. Pulmonary perfusion was performed during retrograde cerebral perfusion in group B (11 patients), whereas the conventional Ueda technique was applied in group A (11 patients). Lung function was evaluated on the basis of intubation time, scoring of chest radiographs at 12 hours after cardiopulmonary bypass, and $\mathrm{PaO}_{2} /$ fraction of inspired oxygen ratio assessed from immediately before the operation to 72 hours after termination of cardiopulmonary bypass.

Results: Study groups were homogeneous for age, sex, interval between symptom onset and surgical operation, previous aortic surgery, preoperative ejection fraction and pulmonary gas exchange function, extent of aortic repair, and concomitant procedures. Cardiopulmonary bypass time, length of retrograde cerebral perfusion, operation time, need for blood substitutes, and surgical revision for bleeding did not differ between treatment groups. Postoperative $\mathrm{PaO}_{2} /$ fraction of inspired oxygen ratios were higher in group $\mathrm{B}$ than in group $\mathrm{A}$, and the difference remained statistically significant throughout the study period. The incidence of prolonged ventilator support ( $>72$ hours) and the severity of the radiographic pulmonary infiltrate score were lower in the perfused group $(18.2 \%$ vs $72.7 \%[P=.015]$ and $0.81 \pm 0.75$ vs $1.8 \pm 0.78[P=.028]$, respectively).

Conclusions: Continuous pulmonary perfusion provided a better preservation of lung function in patients operated on with deep systemic hypothermia.

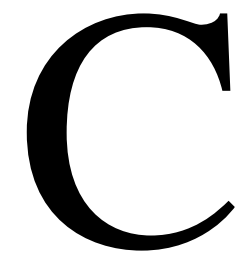
ardiopulmonary bypass is often followed by pulmonary dysfunction, which ranges from clinically silent to very severe lung failure. According to published data, respiratory failure requiring prolonged ventilator support and even acute respiratory distress syndrome (ARDS) are common causes of in-hospital deaths and early and late complications in patients with type A acute aortic dissection operated on with deep hypothermic circulatory arrest (DHCA). In a series of 656 patients operated on with DHCA, Svenson and colleagues ${ }^{1}$ found that respira- 
tory impairment was the cause of death in a total of 36 patients and constituted a complication in 267 patients. In a series of 227 patients operated on with DHCA with and without retrograde cerebral perfusion (RCP), Coselli and associates $^{2}$ reported 88 early and 10 late pulmonary complications and 3 deaths caused by ARDS.

Cumulative knowledge of the mechanisms underlying lung injury indicates that cardiopulmonary bypass (CPB)induced systemic inflammatory response, extensive lung sequestration of neutrophils, interaction between neutrophils and pulmonary endothelium, and ischemia-reperfusion insult are the major determinants.

Recently, Suzuki and coworkers ${ }^{3}$ reported that continuous perfusion of the pulmonary arteries during total CPB in infants with congenital heart disease and pulmonary hypertension preserves lung gas exchange and reduces the need for postoperative mechanical ventilation. The present study was therefore designed to evaluate the effect of continuous pulmonary perfusion during RCP in a prospective series of 22 patients referred for acute type A aortic dissection.

\section{Patients and Methods \\ Study Design}

This is a single-center prospective study performed in accordance with the Declaration of Helsinki on medical research in human patients. Inclusion criteria were a negative history of chronic obstructive pulmonary disease (COPD), along with clear chest radiography and spontaneous ventilation at hospital admission. From January 2001 to December 2001, 39 patients were referred for acute type A aortic dissection to the Division of Cardiac Surgery of the Department of Cardio-Thoracic and Respiratory Sciences, Second University of Naples, "V. Monaldi" Hospital. Seventeen patients were excluded: 9 because ascending artery replacement was performed without open distal anastomosis and 8 because they were intubated at hospital admission or had a positive history of COPD. The trial included 22 informed and consenting patients of both sexes (17 men and 5 women) between 38 and 72 years of age (mean, $53.7 \pm 8.8$ years). Patients were assigned prospectively and alternately to one of 2 treatment groups: group A comprised 11 patients operated on with RCP, and group B comprised 11 patients operated on with RCP and continuous pulmonary perfusion.

\section{Surgical Procedure and Pulmonary Perfusion Protocol}

Anesthesia was induced with moderate doses of fentanyl, midazolam, and a long-acting muscle relaxant and was maintained with isoflurane or sevoflurane in $100 \%$ oxygen and supplemental intravenous opioids. The alpha-stat method was the standard practice in blood gas management. No steroid bolus or aprotinin was used. All operations were performed by the same surgeons (C.M., A.R.). The heart, ascending aorta, aortic arch, and arch vessels were exposed through a median sternotomy in all cases. The CPB circuit comprised a roller pump and membrane oxygenator. Arterial return for CPB was achieved in all cases through femoral arterial cannulation. Branched collagen-sealed grafts (Hemashield
Branched Graft; Meadox Medical, Oakland, NJ) were used. After completion of the distal anastomosis, antegrade CPB was started through the graft, together with rewarming. Myocardial protection was achieved by means of intermittent antegrade crystalloid cardioplegia administered through selective cannulation of the coronary ostia and pericardial cooling with iced slush. RCP was performed in both groups according to the technique of Ueda and coworkers. ${ }^{4}$ Systemic hypothermia at $18^{\circ} \mathrm{C}$ (rectal), cannulation of the superior vena cava (which was occluded with a snare), and cerebral perfusion at a flow rate of 200 to $350 \mathrm{~mL} / \mathrm{m}^{2}$ adjusted to keep jugular venous pressure at $20 \mathrm{~mm} \mathrm{Hg}$ were the main features of this strategy. Head ice packing was performed to further improve cerebral protection. During DHCA, only group B patients underwent continuous pulmonary perfusion with the oxygenated blood at a flow rate of $300 \mathrm{~mL} \cdot \mathrm{m}^{-2} \cdot \mathrm{min}^{-1}$. The perfusate was infused into the pulmonary trunk through a $24 \mathrm{~F}$ cannula and was drained away from the left atrium through an $18 \mathrm{~F}$ vent circuit to secure a bloodless field. The mechanical ventilation was arrested in both groups with positive end-expiratory pressure (PEEP) at $10 \mathrm{~cm}$ $\mathrm{H}_{2} \mathrm{O}$.

\section{Postoperative Respiratory Management}

Inotropic agents were used in the intensive care unit when the cardiac index was less than $3.0 \mathrm{~L} \cdot \mathrm{min}^{-1} \cdot \mathrm{m}^{-2}$, despite volume loading to ensure pulmonary capillary wedge pressures of between 12 and $15 \mathrm{~mm} \mathrm{Hg}$. An 8-hour period of sedation was carried out with incremental doses of morphine sulfate. Mechanical ventilation was performed under the following conditions: tidal volume of 8 to $10 \mathrm{~mL} / \mathrm{kg}$ and PEEP of $5 \mathrm{~cm} \mathrm{H}_{2} \mathrm{O}$. The fraction of inspired oxygen $\left(\mathrm{FIO}_{2}\right)$ and respiratory rates were adjusted to keep $100<$ $\mathrm{PaO}_{2}<150 \mathrm{~mm} \mathrm{Hg}$ and $30<\mathrm{PaCO}_{2}<50 \mathrm{~mm}$, and awakening was allowed when the following targets were achieved: cardiocirculatory stable condition on continuous positive airway pressure ventilation, with dopamine or dobutamine at less than $7.5 \mu \mathrm{g}$. $\mathrm{kg}^{-1} \cdot \min ^{-1}$, chest drainage of less than $100 \mathrm{~mL} / \mathrm{h}$, pulmonary capillary wedge pressure of less than $15 \mathrm{~mm} \mathrm{Hg}$, urine output of greater than $50 \mathrm{~mL} / \mathrm{h}$, and patient warm and cooperative. Patients were extubated when awake at spontaneous continuous positive airway pressure ventilation with pressure-assisted spontaneous breathing of less than $15 \mathrm{~mm} \mathrm{Hg}$ and PEEP of less than $5 \mathrm{~cm} \mathrm{H}_{2} \mathrm{O}$ and with $\mathrm{FIO}_{2}$ of $40 \%$, if $\mathrm{PaO}_{2}$ was greater than $80 \mathrm{~mm} \mathrm{Hg}, \mathrm{PaCO}_{2}$ was less than $50 \mathrm{~mm} \mathrm{Hg}$, tidal volume was greater than $10 \mathrm{~mL} / \mathrm{kg}$, and respiratory rate was 15 to 20 breaths/min.

\section{Assessment of Lung Function}

In all patients arterial blood gas measurements were collected at baseline and at 9 postoperative time intervals: approximately 1, 2, $4,8,16,24,36,48$, and 72 hours after the end of the procedure. The $\mathrm{PaO}_{2} / \mathrm{FIO}_{2}$ ratio was used as the parameter of lung function. Chest radiography was performed 24 hours after admission to the intensive care unit. Scoring of chest radiographs was performed by a blinded radiologist according to the Lung Injury Score proposed by Murray and colleagues, ${ }^{5}$ ranging from 0 (no infiltrate) to 4 (extensive alveolar consolidation).

\section{Other Intraoperative and Postoperative Parameters}

For each patient, demographic data, perioperative and postoperative data (length of DHCA, CPB time, operation time, number of 
TABLE 1. Patient profiles

\begin{tabular}{|c|c|c|c|}
\hline Variables & $\begin{array}{c}\text { Group A } \\
\text { (RCP) }\end{array}$ & $\begin{array}{c}\text { Group B } \\
(\mathrm{RCP}+\mathrm{PP})\end{array}$ & $\begin{array}{c}P \\
\text { value }\end{array}$ \\
\hline Age & $56.2 \pm 10.2$ & $51.3 \pm 6.8$ & NS \\
\hline \multicolumn{4}{|l|}{ Sex } \\
\hline Male & $10(90.9)$ & $7(63.6)$ & NS \\
\hline Female & $1(9.1)$ & $4(36.4)$ & NS \\
\hline Interval symptoms-surgery & $37.6 \pm 54.7$ & $38.6 \pm 21.3$ & NS \\
\hline Hemodynamic instability & $2(18.2)$ & $3(27.3)$ & NS \\
\hline \multicolumn{4}{|l|}{ Extent of aortic repair } \\
\hline $\begin{array}{l}\text { Ascending aorta with } \\
\text { hemiarch }\end{array}$ & $9(81.8)$ & $10(90.1)$ & NS \\
\hline Total arch replacement & $2(18.2)$ & $1(9.1)$ & NS \\
\hline $\begin{array}{l}\text { Concomitant aortic valve } \\
\text { replacement }\end{array}$ & $2(18.2)$ & $2(18.2)$ & NS \\
\hline $\begin{array}{l}\text { Concomitant aortic valve } \\
\text { resuspension }\end{array}$ & $1(9.1)$ & $2(18.2)$ & NS \\
\hline Concomitant CABG & $3(27.3)$ & $1(9.1)$ & NS \\
\hline
\end{tabular}

blood units used, and need for $>72$ hours of ventilator support), postoperative inotropic support, and hospital outcome were recorded.

\section{Study Assessment and Statistical Analysis}

The primary efficacy assessment was a comparison between the 2 groups of patients who experienced pulmonary complications. Pulmonary complication was defined as the need for mechanical ventilation for more than 72 hours because of respiratory performance not satisfying the extubation criteria defined above. Secondary assessment included comparison of lung function through $\mathrm{PaO}_{2} / \mathrm{FIO}_{2}$ ratio and chest radiography score. Continuous variables are presented as means $\pm \mathrm{SD}$. Discrete variables are presented as counts and percentages. The Wilcoxon rank sum test was used for the analysis of continuous variables, and the Fisher exact test was used for analysis of discrete variables. As for $\mathrm{PaO}_{2} / \mathrm{FIO}_{2}$ ratio analysis, 1-way analysis of variance for repeated measurements was used. All computations were performed with the SPSS v.10.1 (SPSS Inc, Chicago, Ill) statistical software package.

\section{Results}

\section{Surgical Procedures, Extracorporeal Circulation, and Blood Substitute Transfusion}

The study groups were homogeneous for age, sex, interval between symptom onset and surgical treatment, preoperative hemodynamic instability, and previous aortic surgery. There was no statistically significant difference between the 2 groups for the extent of surgical repair or associated procedures. Ascending aorta with hemiarch replacement was performed in $9(81.8 \%)$ patients in group A and in 10 $(90.9 \%)$ patients in group B. Total arch replacement (en bloc or with branched grafts) was performed in 2 (18.2\%) patients in group A and in 1 (9.1\%) patient in Group B. Patient profiles and surgical procedures are shown in Table 1. Length of $\mathrm{CPB}$ time and operative time were comparable
TABLE 2. Outcomes and operative variables

\begin{tabular}{lccc}
\hline Variables & $\begin{array}{c}\text { Group A } \\
\text { (RCP) }\end{array}$ & $\begin{array}{c}\text { Group B } \\
\text { (RCP + PP) }\end{array}$ & $\boldsymbol{P}$ value \\
\hline $\begin{array}{l}\text { Postoperative LV ejection } \\
\quad \text { fraction }\end{array}$ & $49.1 \pm 10.4$ & $50.1 \pm 8.0$ & NS \\
High inotropic support & $3(27.3)$ & $3(27.3)$ & NS \\
Hospital mortality & $2(18.2)$ & $1(9.1)$ & NS \\
Permanent neurological & $1(9.1)$ & $2(18.2)$ & NS \\
$\quad$ dysfunction & & & \\
Transient neurological & $2(18.2)$ & 0 & NS \\
$\quad$ dysfunction & & & \\
DHCA time & $41.9 \pm 20.2$ & $29 \pm 12.3$ & NS \\
CPB time & $182.2 \pm 53$ & $176.4 \pm 77.8$ & NS \\
Operation time & $457 \pm 44.3$ & $451 \pm 58.2$ & NS \\
Total units of blood substitute & $7 \pm 4.4$ & $4.6 \pm 2.5$ & NS \\
$\quad$ Packed red cell & $3.2 \pm 1.1$ & $2.4 \pm 1.3$ & NS \\
$\quad$ Fresh-frozen plasma & $3.8 \pm 3.8$ & $2.2 \pm 2.2$ & NS \\
Surgical revision of bleeding & $2(18.2)$ & $2(18.2)$ & NS \\
\hline
\end{tabular}

$P P$, Pulmonary perfusion; $L V$, left ventricular; $N S$, not significant.

(group A, $182.1 \pm 53.1$ minutes; group B, $176.4 \pm 77.8$ minutes). No statistically significant difference emerged in blood substitute and incidence of surgical revisions for bleeding between treatment groups. Groups were homogeneous for postoperative left ventricular ejection fraction (echocardiographic estimation) and level of inotropic support. In particular, high inotropic support during the first 3 postoperative days was defined as dobutamine or dopamine use of greater than $5 \gamma \cdot \mathrm{kg}^{-1} \cdot \min ^{-1}$, enoximone of greater than $10 \gamma \cdot \mathrm{kg}^{-1} \cdot \min ^{-1}$, and norepinephrine at any dosage.

\section{In-hospital Mortality}

The overall hospital mortality was $13.6 \%$, with no significant difference between groups. Deaths were due to multiple organ failure in 1 patient, low cardiac output syndrome in 1 patient, and ARDS in 1 patient. No correlation emerged between causes of death and surgical treatment. Table 2 reports clinical outcomes and perioperative variables.

\section{In-hospital Morbidity}

The overall permanent neurological dysfunction rate reached $9.1 \%$ ( 1 patient in each group). Notably, there was no phrenic nerve or recurrent laryngeal nerve dysfunction. The overall temporary neurological dysfunction rate was 9.1\% (2 patients in group A). No significant difference emerged between study groups. The rate of renal failure (creatinine level $>3.0 \mathrm{mg} / \mathrm{dL}$ or anuria treated with hemofiltration) and hepatic failure (total bilirubin level $>3.0$ $\mathrm{mg} / \mathrm{dL}$ and a 3-fold rise in glutamate-pyruvate transaminase in the absence of myocardial or muscular damage) reached $4.54 \%$ and $9.1 \%$, respectively, with no differences between the groups. 


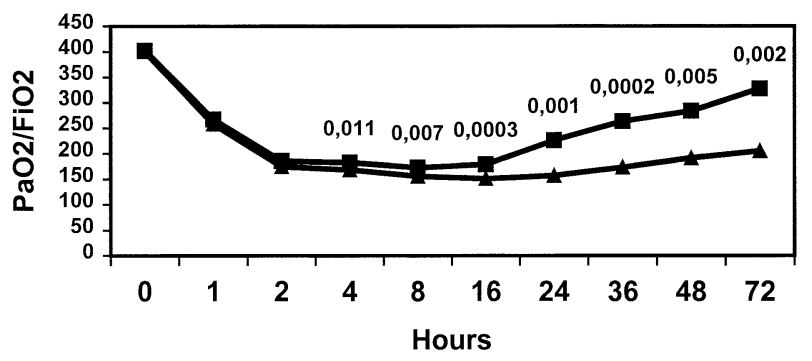

- Group A - -Group B

Figure 1. $\mathrm{PaO}_{2} / \mathrm{FlO}_{2}$ ratio trends.

\section{Lung Function}

Figure 1 reports $\mathrm{PaO}_{2} / \mathrm{FIO}_{2}$ ratio patterns in study groups. In both groups preoperative gas exchange was similar: the $\mathrm{PaO}_{2} / \mathrm{FIO}_{2}$ ratio decreased gradually, reaching its nadir between 8 and 16 hours after CPB, and then it started recovering. At each measuring point beyond 4 hours after CPB, the $\mathrm{PaO}_{2} / \mathrm{FIO}_{2}$ ratio of the perfused group was significantly higher than that of the control group. Analysis to detect differences among the sampling points within each group disclosed a statistically significant difference between baseline $\mathrm{PaO}_{2} / \mathrm{FIO}_{2}$ values and postoperative measurements through all the experimentation, irrespective of surgical treatment. Mean length of ventilator support was $61.1 \pm$ 10.6 hours in group A and $29.7 \pm 12.7$ hours in group B. Consequently, the rate of pulmonary complications (need for mechanical ventilation for more than 72 hours) was significantly lower $(72.7 \%$ vs $18.2 \%, P=.015)$ in the perfused group (Figure 2). Figure 3 reports chest radiographic scoring. The mean scores in group $\mathrm{A}$ and group $\mathrm{B}$ were $1.8 \pm 0.78$ and $0.81 \pm 0.75$, respectively. Again, this difference was statistically significant $(P=.028)$.

\section{Discussion}

The present prospective study in human patients undergoing surgical repair of acute type A aortic dissection by means of DHCA demonstrated that continuous pulmonary perfusion favorably affects postoperative lung function, as supported by better preserved postoperative lung gas exchange $\left(\mathrm{PaO}_{2} /\right.$ $\mathrm{FIO}_{2}$ ratio) and reduced ventilator support. Despite the improvement of the extracorporeal circulation equipment, including oxygenator, blood pump, and arterial filter, pulmonary dysfunction that occurs after CPB remains common, even if it is not accompanied by relevant clinical correlates. The pathogenesis of this syndrome, which is multifactorial and still not completely elucidated, has been extensively reviewed in a recent authoritative article. ${ }^{6}$ In this context ischemia-reperfusion injury represents a major determinant. Indeed, it exacerbates functional and structural damage of the endothelium and promotes extensive neutrophil sequestration in the lung. ${ }^{7-9}$ Experimental studies dem-

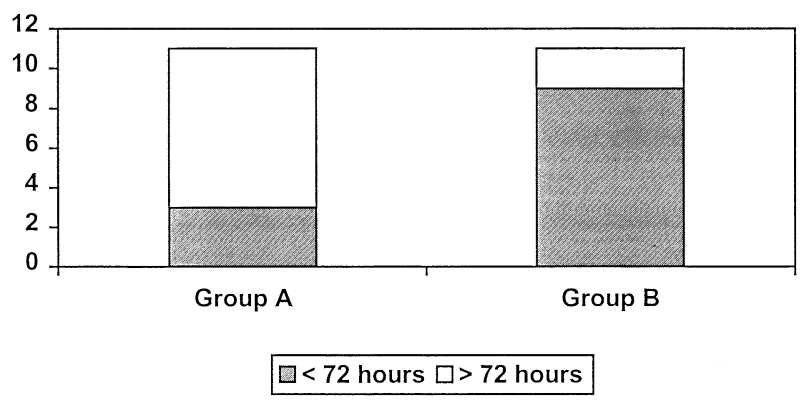

Figure 2. Incidence of prolonged ventilator support.

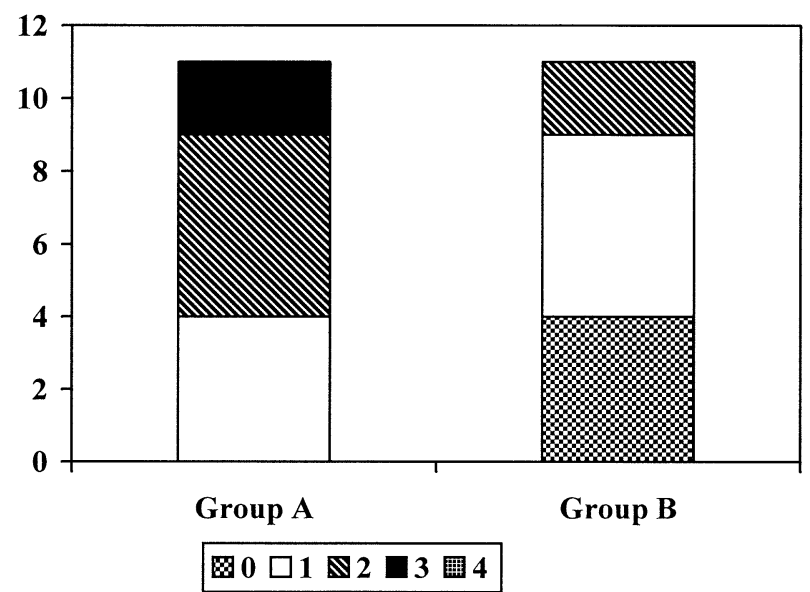

Figure 3. Chest radiographic scoring.

onstrated that with less deprivation of blood flow in the pulmonary arteries, there is less severe subsequent lung injury. ${ }^{10-12}$ On the other hand, the role of bronchial flow in preventing lung ischemia is still controversial. ${ }^{13-14}$ Serraf and coworkers ${ }^{15}$ demonstrated, in a piglet model, that lowflow lung perfusion during total CPB prevents depletion of tissue adenosine triphosphate stores and $\mathrm{PaO}_{2}$. More recently Suzuki and colleagues ${ }^{3,16}$ assessed the effect of continuous pulmonary perfusion during total $\mathrm{CPB}$ in human subjects. The effectiveness of this approach is evident both in the preservation of postoperative lung gas exchange function and in reduced length of mechanical ventilation. Further lung perfusion reduced neutrophil sequestration in the lung and attenuated neutrophil-endothelial interaction. Optimal flow rates and temperature for the continuous pulmonary perfusion are still under investigation. There is experimental evidence that flow rates exceeding $25 \%$ of the systemic blood flow result in less severe pulmonary dysfunction. ${ }^{17}$ Other studies suggest $35 \mathrm{~mL} \cdot \mathrm{kg}^{-1} \cdot \mathrm{min}^{-1}$ as the protective amount of blood support, ${ }^{15}$ whereas the above-mentioned studies in human subjects were performed with $30 \mathrm{~mL} \cdot \mathrm{kg}^{-1} \cdot \min ^{-1}$ blood support. Pulmonary perfusion in this study was performed at $300 \mathrm{~mL} / \mathrm{m}^{2}$ and 
$18^{\circ} \mathrm{C}$. Two different factors influenced the choice of such a perfusion protocol: core cooling on CPB and need for a perfusate temperature associated with a lower pulmonary vascular resistance to exert a more uniform washout of the pulmonary vasculature and to avoid risk of injury to the alveolocapillary membrane. To the best of our knowledge, no previous study has investigated the effectiveness of pulmonary perfusion in patients with type A acute dissection operated on with DHCA. Apart from lower operative temperature, some peculiarities are inherent to this experimental model. First, circulatory arrest prevents both bronchial and pulmonary artery flow, thus determining complete lung ischemia. Second, bronchial arteries arising from the inner curvature of the aortic arch might be affected both by the dissecting process and by the surgical procedure (distal aortic wall reinforcement) so that lungs might become completely dependent on pulmonary artery flow. The overall incidence of pulmonary complications in this study is comparable with those reported elsewhere. ${ }^{1,2}$ As demonstrated by $\mathrm{PaO}_{2} / \mathrm{FIO}_{2}$ ratio trends, $\mathrm{CPB}$ affected lung function in both groups. Nevertheless, pulmonary perfusion exerted a protective effect, and lung gas exchange in group $\mathrm{B}$ at each measuring point beyond 4 hours after $\mathrm{CPB}$ was significantly higher than that of the control group. These patterns are almost comparable with those reported by Suzuki and coworkers. ${ }^{3}$ In particular, lung gas exchange normalization was slower in both groups, and perfused patients experienced a significant postoperative worsening of the $\mathrm{PaO}_{2} / \mathrm{FIO}_{2}$ ratio. This might be explained by the older age of our study sample, the longer CPB times, the lower operative temperature, and the above-mentioned pathologic and technical features of this setting. In this respect it is important to stress that study groups proved homogeneous in the extent of surgical treatment and in the length of CPB times. On the other hand, continuous pulmonary perfusion resulted in significantly lower duration of intubation and better chest radiographic scoring. These results are consistent with those of published series. ${ }^{3,16}$

\section{Study Limitations}

Some limitations of the study are to be considered. First, the number of patients in each group is relatively small, implying some weakness of the statistical results. This is clearly a result of the single-center design of the trial itself, which, on the other hand, guarantees the uniform perioperative management of the patient population throughout the experimentation. Second, our study might have lacked a third group in which pulmonary perfusion with complete lung deflation (no PEEP) during RCP should have been applied. This approach might have disclosed the contribution of PEEP to this protective strategy. There is much evidence in the literature supporting the application of PEEP when mechanical ventilation is stopped, ${ }^{18,19}$ and we advocate its use as standard practice in procedures requiring long total
CPB times or DHCA. Furthermore, we did not directly measure lung ischemia or bronchial arterial flow or estimate the inflammatory response in the 2 groups. Consequently, we were unable to comment on the degree of ischemia and eventual contribution of bronchial flow impairment. As far as the inflammatory response is concerned, both groups were exposed to the same type of extracorporeal circuit for a similar period, underwent the same extent of operative trauma, and received comparable amounts of blood units, and thus the degree of inflammation should be considered the same. Finally, the inclusion criteria were clearly aimed to select a homogeneous study population (freedom from COPD and normal preoperative respiratory ratios); nevertheless, the role of some confounding factors (extracorporeal circulation length, blood requirements, and postoperative cardiac function) was difficult to assess because of the unpredictability of surgical procedure and, above all, because of the limited study sample. Inferences from the study results to the routine clinical environment might need careful consideration.

\section{Conclusions}

Our study suggests that continuous pulmonary perfusion might have a beneficial effect on pulmonary function during aortic procedures performed during deep hypothermia. Further studies with larger groups of patients are needed.

\section{References}

1. Svenson LG, Crawford ES, Hess KR, Coselli JS, Raskin S, Shenach SA. Deep hypothermia with circulatory arrest: determinants of stroke and early mortality in 656 patients. J Thorac Cardiovasc Surg. 1993; 106:19-31.

2. Coselli JS, Bueket S, Djukanovic B. Aortic arch surgery: current treatment and results. Ann Thorac Surg. 1995;59:19-27.

3. Suzuki T, Fukuda T, Ito T, Inoue Y, Cho Y, Kashima I. Continuous pulmonary perfusion during cardiopulmonary bypass prevents lung injury in infants. Ann Thorac Surg. 2000;69:602-6.

4. Ueda Y, Miki S, Kusuhara K, Okita Y, Tahata T, Yamanaka K. Surgical treatment of aneurysm or dissection involving the ascending aorta and aortic arch, utilizing circulatory arrest and retrograde cerebral perfusion. J Cardiovasc Surg. 1990;31:553-8.

5. Murray JF, Matthay MA, Luce JM, Flick MR. An expanded definition of the adult respiratory distress syndrome. Am Rev Respir Dis. 1988; 138:720-3.

6. Asimakopoulos G, Smith PLC, Ratnanuga C, Taylor KM. Lung injury and acute respiratory distress syndrome after cardiopulmonary bypass. Ann Thorac Surg. 2000;69:602-6.

7. Messent M, Griffith MJD, Evans TW. Pulmonary vascular reactivity and ischemia reperfusion injury in the rat. Clin Sci. 1993;85:71-5.

8. McCord JM. Oxygen-derived free radicals in postischemic tissue injury. N Engl J Med. 1985;312:159-63.

9. Miller BE, Levy JH. The inflammatory response to cardiopulmonary bypass. J Cardiothorac Vasc Anesth. 1997;11:335-66.

10. Kuratani T, Matsuda H, Sawa Y, Kaneko M, Nakano S, Kawashima Y. Experimental study in a rabbit model of ischemia-reperfusion lung injury during cardiopulmonary bypass. J Thorac Cardiovasc Surg. 1992;103:564-8.

11. Friedman M, Sellke FW, Wang SY, Weintraub RM, Johnson RG. Parameters of pulmonary injury after total or partial cardiopulmonary bypass. Circulation. 1994;90:II262-8.

12. Chai PJ, Williamson A, Lodge AJ, et al. Effects of ischemia on pulmonary dysfunction after cardiopulmonary bypass. Ann Thorac Surg. 1999;67:731-5. 
13. Schlensak C, Doenst T, Beyersdorf F. Lung ischemia during cardiopulmonary bypass. Ann Thorac Surg. 2000;70:337-8.

14. Ungerleider RM. Reply to "Lung ischemia during cardiopulmonary bypass" [letter]. Ann Thorac Surg. 2000;70:338-9.

15. Serraf A, Robotin M, Bonnet N, et al. Alteration of the neonatal pulmonary physiology after total cardiopulmonary bypass. J Thorac Cardiovasc Surg. 1997;114:1061-9.

16. Suzuki T, Ito T, Kashima I, Teruya K, Fukuda T. Continuous perfusion of pulmonary arteries during total cardiopulmonary bypass favorably affects levels of circulating adhesion molecules and lung function. J Thorac Cardiovasc Surg. 2001;122:242-8.
17. Kuratani T, Sawa Y, Shimazaki Y, Kadoba K, Matsuada H. Ultrastructural assessment of postoperative lung injury: the effect of bronchial blood flow during cardiopulmonary bypass. J Jpn Assoc Thorac Surg. 1994;42:1132-6.

18. Loekinger A, Kleinsasser A, Linder KH, Margreiter J, Keller C, Hoermann C. Continuous positive airway pressure at $10 \mathrm{~cm} \mathrm{H}_{2} \mathrm{O}$ during cardiopulmonary bypass improves postoperative gas exchange. Anesth Analg. 2000;91:522-7.

19. Cogliati AA, Menichetti A, Tritapepe L, Conti G. Effects of three techniques of lung management on pulmonary function during cardiopulmonary bypass. Acta Anaesthesiol Belg. 1996;47:73-80.

\section{Targeted}

The Journal of Thoracic and Cardiovascular Surgery gives you two tables of contents.

The condensed table of contents tells you at a glance what topics and authors are presented each month. The expanded table of contents gives you a brief abstract of each article. You select only those articles of most interest to you for further reading. 